Lakmini Bulathsinhala, MPH ${ }^{1}$, Nevaashni Eleangovan, BSC ${ }^{1}$, Liam G. Heaney, MD ${ }^{2}$, Andrew Menzies-Gow, PhD, FRCP ${ }^{3}$, Peter G Gibson, MBBS FRACP ${ }^{4,5}$, Matthew Peters, $\mathrm{PhD}, \mathrm{MD}^{6}$, Mark Hew, MBBS, PhD, DIC ${ }^{7}$, Job FM van Boven, $\mathrm{PharmD}, \mathrm{PhD}^{8}$, Lauri Lehtimäki, $\mathrm{MD}^{9}$, Eric van Ganse, $\mathrm{MD}, \mathrm{PhD}, \mathrm{FRCP}^{10}$, Manon Belhassen, $\mathrm{PhD}^{10}$, Erin Harvey, $\mathrm{PhD}^{4,5}$, Luis Perez de Llano, $\mathrm{MD}, \mathrm{PhD}^{11}$, Anke H. Maitland-van der Zee, PharmD, $\mathrm{PhD}^{12}$, Nikolaos Papadopoulos, MD, PhD ${ }^{13,24}$, J. Mark FitzGerald, MB, MD, FRCPI, FERS, FRCPC, FACP, FACCP ${ }^{14}$, Celeste Porsbjerg, MD, $\mathrm{PhD}^{15}$, G. Walter Canonica, MD, FAAAAI ${ }^{16}$, Vibeke Backer, MD, DMSci ${ }^{15}$, Chin Kook Rhee, MD, $\mathrm{PhD}^{17}$, Katia Verhamme, $\mathrm{MD}, \mathrm{PhD}^{18}$, Roland Buhl, $\mathrm{MD}^{19}$, Borja G Cosio, $\mathrm{MD}, \mathrm{PhD}^{20}$, Victoria Carter, $\mathrm{BSc}^{1}$, Chris Price, LL.B. ${ }^{1}$, Thao Le, BComm ${ }^{1}$, Martina Stagno d'Alcontres, $\mathrm{PhD}^{21}$, Gokul Gopalan, $\mathrm{MD}^{22}$, Trung Tran, MD, $\mathrm{PhD}^{22}$, David Price, FRCGP ${ }^{1,21,23}$

${ }^{I}$ Optimum Patient Care, Cambridge, UK, ${ }^{2}$ British Thoracic Society UK Severe Asthma Network and National Registry on Difficult Asthma, Queen's University Belfast, Belfast, Northern Ireland, ${ }^{3} U K$ Severe Asthma Network, Royal Brompton \& Harefield NHS Foundation Trust, London, UK, ${ }^{4}$ Australasian Severe Asthma Network, Priority Research Centre for Healthy Lungs, University of Newcastle, Newcastle, Australia, ${ }^{5}$ Hunter Medical Research Institute, Department of Respiratory and Sleep Medicine, John Hunter Hospital, New Lambton Heights, Australia, ${ }^{6}$ University of Sydney Medical School, Sydney, Australia, ${ }^{7}$ Alfred Health, Melbourne, Australia, ${ }^{8}$ Department of General Practice, Groningen Research Institute for Asthma and COPD (GRIAC), University Medical Center Groningen, University of Groningen, Groningen, The Netherlands, ${ }^{9}$ Allergy Centre, Tampere University Hospital; University of Tampere, Tampere, Finland, ${ }^{10}$ Claude Bernard University Lyon, Lyon, France, ${ }^{11}$ Spanish Society of Pulmonology and Thoracic Surgery, Madrid, Spain, ${ }^{12}$ University of Amsterdam, Amsterdam, The Netherlands, ${ }^{13}$ University of Athens, Athens, Greece, ${ }^{14}$ The Institute for Heart Lung Health, Vancouver, Canada, ${ }^{15}$ Bispebjerg Hospital, Copenhagen University, Copenhagen, Denmark, ${ }^{16}$ Personalized Medicine Asthma \& Allergy Clinic, Humanitas University \& Research Hospital, Milan, Italy, \& SANI-Severe Asthma Network Italy. ${ }^{17}$ The Catholic University of Korea, Seoul, South Korea, ${ }^{18}$ Ghent University, Gent, Belgium, ${ }^{19}$ Mainz University Hospital, Mainz, Germany, ${ }^{20}$ Son Espases University Hospita-IdISBa-Ciberes, Mallorca, Spain, ${ }^{21}$ Observational and Pragmatic Research Institute, Singapore, ${ }^{22}$ AstraZeneca, Gaithersburg, USA, ${ }^{23}$ Academic Primary Care, University of Aberdeen, Aberdeen, UK, ${ }^{24}$ University of Manchester, UK

*Corresponding author: Prof David B Price, Academic Primary Care, Division of Applied Health Sciences, University of Aberdeen, Polwarth Building, Foresterhill, Aberdeen, UK AB25 2ZD.

E-mail: dprice@opri.sg

Tel: +6568029724 
Lakmini Bulathsinhala

Nevaashni Eleangovan

Liam G. Heaney

Andrew Menzies-Gow

Peter G Gibson

Matthew Peters

Mark Hew

Job FM van Boven

Lauri Lehtimäki

Eric van Ganse

Manon Belhassen

Erin Harvey

Luis Perez de Llano

Anke H. Maitland-van der Zee

Nikolaos Papadopoulos

J Mark FitzGerald

Celeste Porsbjerg

G. Walter Canonica

Vibeke Backer

Chin Kook Rhee

Katia Verhamme

Roland Buhl

Borja G Cosio

Victoria Carter

Chris Price

Thao Le

Martina Stagno d'Alcontres

Gokul Gopalan

Trung Tran

David Price lakmini@optimumpatientcare.org

neva@optimumpatientcare.org

1.heaney@qub.ac.uk

A.Menzies-Gow@rbht.nhs.uk

peter.gibson@newcastle.edu.au

Matthew.Peters@health.nsw.gov.au

M.Hew@alfred.org.au

jobvanboven@gmail.com

Lauri.Lehtimaki@uta.fi

eric.van-ganse@univ-lyon1.fr

manon.belhassen@univ-lyon1.fr

erin.harvey@newcastle.edu.au

eremos26@hotmail.com

a.h.maitland@amc.uva.nl

ngpallergy@gmail.com

mark.fitzgerald@vch.ca

porsbjerg@dadlnet.dk

canonica@unige.it

backer@dadlnet.dk

chinkook77@gmail.com

katiak.verhamme@erasmusmc.nl

roland.buhl@unimedizin-mainz.de

borja.cosio@ssib.es

victoria@optimumpatientcare.org

chris@optimumpatientcare.org

thao@optimumpatientcare.org

mstagno@gmail.com

gokulgopalanmd@gmail.com

TranTr@medimmune.com

dprice@opri.sg

$40 \quad$ Funding

41 This study is co-funded by Optimum Patient Care Global and AstraZeneca. 


\section{Declarations of Interest}

Chris Price, Lakmini Bulathsinhala, Nevaashni Eleangovan, Thao Le, Martina Stagno d'Alcontres, and Victoria Carter are employees of Optimum Patient Care, a co-funder of the International Severe Asthma Registry. Trung Tran is an employee of AstraZeneca, a co-funder of the International Severe Asthma Registry. Gokul Gopalan was formerly an employee of AstraZeneca.

Liam Heaney has taken part in advisory boards and given lectures at meetings supported by GlaxoSmithKline, Respivert, Merck Sharpe \& Dohme, Nycomed, Boehringer Ingelheim, Teva, Vectura, Novartis and AstraZeneca. He declares sponsorship for attending international scientific meetings from AstraZeneca, Boehringer Ingelheim, GlaxoSmithKline and Napp Pharmaceuticals; and speaker fees from AstraZeneca, Aerocrine, Hoffman la Roche and Teva.

Andrew Menzies-Gow declares grants from AstraZeneca, Boehringer Ingelheim, GlaxoSmithKline and Hoffman La Roche; consultancy agreements with AstraZeneca and Vectura; personal fees from AstraZeneca, Boehringer Ingelheim, GlaxoSmithKline, Hoffman La Roche, Napp Pharmaceuticals, Novartis, Teva and Vectura; non-financial support from AstraZeneca, Boehringer Ingelheim and Napp Pharmaceuticals; and payment for travel expenses to international conferences from AstraZeneca, Boehringer Ingelheim and Napp Pharmaceuticals.

Peter Gibson declares grants from AstraZeneca, GlaxoSmithKline and Novartis; and personal fees from AstraZeneca and GlaxoSmithKline.

Matthew Peters declares personal fees and non-financial support from AstraZeneca and GlaxoSmithKline.

Mark Hew declares grants and other advisory board fees from AstraZeneca, GlaxoSmithKline, Novartis and Seqirus, with all payments to his institutional employer.

Lauri Lehtimäki declares personal fees for consultancy and lectures from AstraZeneca, Boehringer Ingelheim, Chiesi, GlaxoSmithKline, Mundipharma, Novartis, Orion Pharma and Teva; and personal fees for consultancy from ALK. 
Eric van Ganse declares grants from ALK ABELLO, Bayer, BMS, GlaxoSmithKline, Merck Sharp and

Dohme; and personal fees from ALK ABELLO, AstraZeneca, Bayer, BMS, Boehringer Ingelheim,

GlaxoSmithKline, IMS, and Merck Sharp and Dohme.

Luis Perez de Llano declares grants from AstraZeneca, Chiesi and Teva; personal fees from AstraZeneca, Boehringer Ingelheim, Chiesi, Esteve, GlaxoSmithKline, Mundipharma, Novartis, Sanofi and Teva; non-financial support from Boehringer Ingelheim, Esteve, GlaxoSmithKline, Menarini, Mundipharma, Novartis and Teva.

Anke H. Maitland-van der Zee declares unrestricted grants from GlaxoSmithKline and personal fees for advisory board activities from AstraZeneca.

Nikolaos Papadopoulos declares personal fees for advisory board activities from BIOMAY, Faes Farma, HAL, Novartis and Nutricia Research; consultancy fees from MEDA, Menarini and Novartis; institution grant from Menarini; personal fees for speaker/chairperson from Abbvie, Danone, MEDA, MSD, Novartis and Omega Pharma.

Chin Kook Rhee declares consultancy and lecture fees from AstraZeneca, Boehringer Ingelheim, GlaxoSmithKline, MSD, Mundipharma, Novartis, Sandoz, Takeda and Teva-Handok.

Katia Verhamme works for a research group which in the past received unconditional research grants from Yamanouchi, Boehringer Ingelheim, Novartis and GlaxoSmithKline.

Roland Buhl declares personal fees from AstraZeneca, Boehringer Ingelheim, Chiesi, Novartis, Roche and Teva, as well as grants to Mainz University from Boehringer Ingelheim, GlaxoSmithKline, Novartis and Roche.

Borja G Cosio declares grants from Chiesi; personal fees for advisory board activities from Chiesi and AstraZeneca; and payment for lectures/speaking engagements from Chiesi, Novartis, Menarini and AstraZeneca.

David Price declares board membership with Aerocrine, Amgen, AstraZeneca, Boehringer Ingelheim, 
Pharmaceuticals; consultancy agreements with Almirall, Amgen, AstraZeneca, Boehringer Ingelheim, Chiesi, GlaxoSmithKline, Mylan, Mundipharma, Napp, Novartis, Pfizer, Teva Pharmaceuticals, Theravance; grants and unrestricted funding for investigator-initiated studies (conducted through Observational and Pragmatic Research Institute Pte Ltd) from Aerocrine, AKL Research and Development Ltd, AstraZeneca, Boehringer Ingelheim, British Lung Foundation, Chiesi, Mylan, Mundipharma, Napp, Novartis, Pfizer, Regeneron Pharmaceuticals, Respiratory Effectiveness Group, Sanofi Genzyme, Teva Pharmaceuticals, Theravance, UK National Health Service, Zentiva (Sanofi Generics); payment for lectures/speaking engagements from Almirall, AstraZeneca, Boehringer Ingelheim, Chiesi, Cipla, GlaxoSmithKline, Kyorin, Mylan, Merck, Mundipharma, Novartis, Pfizer, Regeneron Pharmaceuticals, Sanofi Genzyme, Skyepharma, Teva Pharmaceuticals; payment for manuscript preparation from Mundipharma, Teva Pharmaceuticals; payment for the development of educational materials from Mundipharma, Novartis; payment for travel/accommodation/meeting expenses from Aerocrine, AstraZeneca, Boehringer Ingelheim, Mundipharma, Napp, Novartis, Teva Pharmaceuticals; funding for patient enrolment or completion of research from Chiesi, Novartis, Teva Pharmaceuticals, Zentiva (Sanofi Generics); stock/stock options from AKL Research and Development Ltd which produces phytopharmaceuticals; owns $74 \%$ of the social enterprise Optimum Patient Care Ltd (Australia and UK) and 74\% of Observational and Pragmatic Research Institute Pte Ltd (Singapore); and is peer reviewer for grant committees of the Efficacy and Mechanism Evaluation programme, and Health Technology Assessment.

Vibeke Backer declares collaboration, consultancy, unrestricted grants and lecture fees from AstraZeneca, TEVA, Sanofi, Boehringer Ingelheim, GlaxoSmithKline, MSD, Mundipharma, Novartis, and Sandoz, furthermore advisory board at AstraZeneca, GSK, ALK-Abello, TEVA, Sanofi, and Novartis.

Celeste Porsbjerg, Erin Harvey, G Walter Canonica, J Mark FitzGerald, Job van Boven, and Manon Belhassen declare no relevant conflicts of interest concerning this paper. 
119 All existing severe asthma registries in the world were either country or region specific. Most 120 importantly, none shared a common set of variables for data collection. This impedes data sharing and 121 subsequently disallows data pooling to conduct research with robust sample size.

122 What does this article add to our knowledge?

123 This paper depicts a systematic method of soliciting group consensus on a topic that entails a spectrum 124 of choices and viewpoints.

125 How does this study impact our current management guidelines?

126 Using the standardized minimal list of variables identified by our study, we hope to achieve data 127 interoperability between severe asthma registries across the globe and subsequently improve patient management guidelines in severe asthma. 
129 Abstract

130 Background: The lack of centralised data on severe asthma has resulted in a scarcity of information 131 about the disease and its management. The development of a common data collection tool for the 132 International Severe Asthma Registry (ISAR) will enable standardised data collection, subsequently 133 enabling data interoperability.

Objectives: To create a standardised list of variables for the first international registry for severe asthma via expert consensus.

Methods: A modified Delphi process was used to reach consensus on a minimum set of variables to capture in ISAR: the core variables. The Delphi panel brought together 27 international experts in the field of severe asthma research. The process consisted of three iterative rounds. In each round, all Delphi panel members were issued an electronic ISAR Delphi workbook to complete and return to the ISAR Delphi administrator. Workbooks and result summaries were anonymously distributed by the Delphi administrator to all panel members at subsequent rounds. Finalisation of the core variable list was facilitated by two face-to-face meetings.

Results: Of the initial 747 selected variables, the Delphi panel reached a consensus on 95 . The chosen variables will allow severe asthma to be assessed against patient demographics and medical history, patient-reported outcomes, diagnostic information and clinical characteristics. Physician-reported outcomes such as non-adherence and information about treatment and management strategies will also be recorded.

Conclusion: This is the first global attempt to generate an international severe asthma registry using a common set of core variables to ensure that data collected across all participating countries are standardised. 


\section{Abbreviation}

A\&E

ACQ

ACT

ADEPT

Anti-IgE

Anti-IL-5

ATS

BMI

BSA

BTS

CRF

CT

DEXA

EMA

ENCePP

ERS

FDA

FENO

$\mathrm{FEV}_{1}$

FVC

GINA

ICS

IgE

ISAR

ISC

LABA

LAMA

LTRA

OCS

OPC

OPCRD

OPRI

$\mathrm{PC}_{20}$

PEF
Accident \& Emergency

Asthma Control Questionnaire

Asthma Control Test

Anonymised Data Ethics \& Protocol Transparency

Anti-Immunoglobulin E Treatment

Anti-Interleukin-5 Treatment

American Thoracic Society

Body Mass Index

Body Surface Area

British Thoracic Society

Case Report Form

Computerised Tomography

Dual Energy X-ray Absorptiometry

European Medicines Agency

European Network of Centres for Pharmacoepidemiology and Pharmacovigilance

European Respiratory Society

Food and Drug Administration

Fractional Exhaled Nitric Oxide

Forced Expiratory Flow in one second

Forced Vital Capacity

Global Initiative for Asthma

Inhaled Corticosteroids

Immunoglobulin $\mathrm{E}$

International Severe Asthma Registry

ISAR Steering Committee

Long-Acting Beta-Agonists

Long-Acting Muscarinic Antagonist

Leukotriene Receptor Antagonist

Oral Corticosteroids

Optimum Patient Care

Optimum Patient Care Research Database

Observational and Pragmatic Research Institute Pte. Ltd.

Concentration of Methacholine/Histamine needed to produce a $20 \%$ decrease in $\mathrm{FEV}_{1}$

Peak Expiratory Flow 


\section{Abbreviation}

R1

Delphi Round 1

R2

Delphi Round 2

R3

Delphi Round 3

RAST

Radioallergosorbent Test

SABA

Short-Acting Beta-Agonists

SAWD

Severe Asthma Web-based Database

SPT

Skin Prick Test

154

155

156 Metrics information:

157 Date: $17^{\text {th }}$ April 2018

158 Abstract word count: 250 words

159 Text word count: 4252 words

160 Number of references: 31 references

161 Number of tables and figures: 3 tables and 2 figures

162 Online supplement: yes, with 4 e-Tables 


\section{Introduction}

Asthma affects $5-15 \%$ of the population worldwide and its prevalence has noticeably increased in recent decades (1). This heterogeneous disease, characterised by variable symptoms including cough, wheeze and dyspnoea, is associated with chronic airway inflammation. Management strategies, including asthma education, are aimed at achieving optimal disease control via minimisation of current symptoms and prevention of acute exacerbations using a stepwise approach to medication (2).

Although most asthma patients have mild to moderate disease symptoms that may be well-controlled with standard treatment, a smaller sub-population remains uncontrolled and/or suffers from severe symptoms. The exact prevalence of severe asthma is uncertain but has been estimated at $5-10 \%$ of the asthma population (3-5). Such patients remain inadequately managed with the current standard of care (3), which includes high-dose inhaled corticosteroids with additional controllers and represent a significant unmet need.

There is compelling evidence to suggest that better standardised care for severe asthma is needed, including the registration of systematic assessment and improved and aligned registries of patients whose symptoms fulfil the criteria for severe asthma (6). Indeed, registries are well established tools for tracking and reporting on the epidemiological attributes of a disease. They are valuable resources which enable treatment benefits and risks to be proactively monitored over time, through the collection of natural history data, and which aid the development of therapeutics and/or diagnostics. They can be used to gather information on disease progression and patient subgroups, facilitate patient recruitment into clinical trials, and generate real world evidence on the safety and cost effectiveness of new therapeutics (7). Notably, registries are increasingly required as part of the post-approval safety monitoring process of regulatory bodies for new treatments (7).

The current registry landscape for severe asthma is viewed as a collection of divergent, national and regional registries. The design, development and maintenance of such registries has typically revolved around specific data collection platforms and drugs, leading to the creation of segregated systems with little or no collaboration between the different collections. Individual registries have limited power due 
to the relative rarity of severe asthma and stringent inclusion criteria. Different objectives and

190 governance rules also exist across different countries and/or organisations. These disparities can lead to

191 country-specific registries collecting different data fields of various quality. These limitations lead to

192 the implementation of only a subset of registry functions, resulting in the collection and analysis of

193 limited data on severe asthma. Pooling data across multiple registries will improve the precision of 194 incidence estimates, aid in identifying rare safety signals, and facilitate the exploration of possible drug195 demographic, drug-disease or drug-drug interactions in different sub-populations of the combined 196 global severe asthma patients (8). To date, several national and regional severe asthma registries exist 197 (9-12), but none has an agreed international focus and standard list of data fields.

198 Using long-standing severe asthma registries from the United Kingdom (UK) (9) and Australia (11, 13), 199 our aim was to gain expert consensus on a standardised list of variables on demographic, clinical 200 characteristics, treatment and comorbidities to establish the first international registry for severe asthma 201 so that data can be seamlessly exchanged between countries and institutions without system-specific 202 differences. 
204

205

206

207

208

209

210

211

212

213

214

215

216

217

218

219

220

221

222

223

224

225

226

227

228

229

\section{Methods}

This study utilised a modified, 3-round Delphi method process (14) to select the common core variables to be collected in the International Severe Asthma Registry (ISAR). Variables were initially selected from previously existing national severe asthma registries. This helped to hasten the process of building the registry data collection framework by integrating real-world data elements that have been tested for feasibility of usage and collection.

\section{Panel selection}

To achieve consensus, it was essential for the Delphi panel to include appropriately qualified and experienced individuals who could provide critical and discrete input toward the issue. The ISAR Delphi panel consisted of 27 experts in the field of severe asthma research. The panel members were invited from 16 different countries (Supplementary Table 1), and were selected according to two or more of the following criteria:

1. Evidence of relevant asthma research published in high-ranking peer reviewed journals (e.g. high number of citations and research items)

2. A history of participation in the development and/or management of one or more severe asthma registries, epidemiological databases and scientific congress committees in a particular country and/or internationally

3. Experience as a medical provider with interest in advancing asthma management in clinical practice.

All the 22 ISAR Steering Committee (ISC) members were included in the list of 27 Delphi panel members, and hence, the Delphi panel was highly representative of the ISC. The five Delphi panel members not on the ISC were: one pharmaco-epidemiologist, one health-economist, two severe asthma clinical researchers, and one severe asthma database manager.

\section{Modified Delphi process}

A modified Delphi process was used to reach consensus (15). The process consisted of three iterative rounds (R1, R2 and R3) (Figure 1) where each Delphi panel member was issued an electronic ISAR 
Delphi workbook to review, provide suggestions and vote to select core variables. Members then return

231 the completed Delphi workbooks anonymously, to the ISAR Delphi administrator within a two-week time frame stipulated for each round. The Delphi administrator directly corresponded with all panel members individually to ensure anonymity of replies and was responsible for disseminating a workbook and result summaries for each round.

\section{Delphi R1}

The Delphi workbook (The ISAR Delphi Workbook Round 1) was developed by consolidating the variable lists for the British (British Thoracic Society (BTS) Difficult Asthma Network) (9) and the Australian (Severe Asthma Web-based Database (SAWD)) (13) severe asthma registry. These variables were chosen as the initial bank of variables due to 15 years of usage and SAWD having the most number of variables amongst the existing severe asthma registries as of 2017. However, as there were 907 variables in both registries combined, and given that there are limited resources available for data collection, this exercise set out to determine not only the most appropriate variables but also to ensure that data collection for such variables can be sustained in a clinical setting.

Information from both registries was formally requested and extracted to develop two sets of variables: there were 115 variables in the "potential core" list (variables common to both registries; please see Table 1 for a sample) and 632 variables in the "suggest" list (variables unique to either registry; please see Table 2 for a sample).

The workbook was developed using Microsoft Excel 2016 MSO (V16.0) and consisted of a two-tab spreadsheet with response-controlled questionnaires. On tab one, displaying the potential core list (Table 1), panel members were required to select an option ("Yes" or "No") via a drop-down menu for each variable, indicating whether they concur that the variable would be part of the ISAR core variable list. Panel members were also encouraged to nominate variables from the suggest variable list (Table 2) on tab two and/or propose new variables. Experts were also encouraged to provide comments for excluding or including variables.

The Delphi workbook was sent to each Delphi panel member electronically, to be completed independently and returned via email to the Delphi administrator. At round closure, the Delphi 
administrator anonymised all returned workbooks and compiled all replies to tabulate frequency of responses, "Yes" and "No", for each variable on the lists.

Variable consensus was then evaluated using summary statistics (frequency counts) generated with a statistical program (Stata 14, StataCorp LLC, Texas, USA). Each "potential core" variable that received a majority $(66.6 \%)$ or more consensus from the Delphi panel was selected as an ISAR core variable. However, with the first-round of results, to exercise rigorous oversight, only variables with $100 \%$ consensus were added to the core list. Variables with less than $50 \%$ consensus were reviewed and removed. All other potential core variables were circulated for another round of review (Delphi R2). In tandem to the potential core, the suggest list of variables was also reviewed to evaluate the number of votes by the Delphi panel. Variables with at least two "Yes" votes were then circulated for another round of review (Delphi R2). The Delphi R1 results were presented to the ISC (much of the Delphi panel consisted of ISC members (22/27)) during the inaugural ISAR Steering Committee meeting in

March 2017.

\section{Delphi R2}

As in $\mathrm{R} 1$, the expert panel was requested to engage in a similar voting process for the Delphi R2 via a limited-response electronic questionnaire (The ISAR Delphi Workbook Round 2). The Delphi R1 summary results and panel member comments ("Reasons") were anonymised and provided in the R2 workbook to facilitate an informed decision. Moreover, "Additional Information" on the use or functionality of these variables in the ISAR registry was provided to aid panel members in their decision. Potential core variables with less than $100 \%$ and greater than $50 \%$ consensus from R1 were included in the R2 workbook. Additionally, suggest variables with at least two or more votes by Delphi panel members were disseminated for a full panel poll in R2.

Delphi R3

The Delphi panel also took part in R3 via a limited-response electronic questionnaire (The ISAR Delphi Workbook Round 3). Suggest variables and potential core variables were vetted concurrently in the same manner in R3, following finalisation of suggest variables during R3 discussions by the Delphi panel. Suggest variables from R2 which had attained more than $50 \%$ consensus and potential core 
variables from $\mathrm{R} 2$ on which a consensus was not reached ( $>50 \%$ and $<66.6 \%$ consensus) were circulated for another round (R3). In addition, due to high relatability, nine of the suggest variables from R2 were consolidated into four variables/questions after discussion at the inaugural Steering Committee meeting. These were: current occupation, age at start of asthma symptoms, environmental allergen test conducted, and current clinical management plan. These variables were added to the R3 workbook to ensure full vetting and review by the panel.

The ISAR core variables were finalised during the second ISAR Research Prioritisation meeting in May 2017. R3 results and all outstanding concerns raised by panel members, such as data field options for variables including ethnicity and occupation, were discussed and resolved at the second Steering Committee face-to-face meeting. The participants were requested to re-evaluate the remaining five undecided variables to arrive at a consensus on which variables would be submitted for another Delphi round and hence, which would be retained or removed from the final ISAR core variable list. The discussion was mediated by the Delphi neutral facilitator, who closed the gap of consensus by reminding the Steering Committee and/or Delphi members of the aim of the ISAR registry and the international study population under consideration. The final core variable list was shared with the Delphi panel in a Case Report Form (CRF). All chosen core variables were represented in the final CRF questionnaire 300 format.

301 All variables that were not selected for the core list at the end of the Delphi process were compiled into a separate list. This list later gave rise to standard bolt-on variables, named "research variables".

303 Research variables are available to be adopted by a participating country-specific registry according to local research interests and capacity to collect and store data. A participating country is encouraged to add variables outside the core list to the country-specific registry, including and/or beyond the research variable list. All the research variables are available to you via Mendeley Data (http://dx.doi.org/10.17632/2zg9v6krbb.1). 
309 For the three types of variable lists shown below, the corresponding variable name and the related

310 meta-data, such as format and response options, are demonstrated in the "ISAR Delphi Process

311 Variables Workbook":

312 1. Sheet 1: Matched "Potential Core" Variables

(List of Matching variables from the BTS and SAWD registries)

2. Sheet 2: Unmatched "Suggest" Variables

3. Sheet 3: Variables disqualified (List of variables removed from the total number of matching and non-matching variables)

318 This data has been deposited into a secure electronic repository via Mendeley Data 


\section{Results}

323 Fifteen of the 27 members of the panel participated in Delphi R1 (55.6\%); 28 of 115 initial potential core variables achieved complete consensus with $100 \%$ agreement for inclusion into the ISAR core variable list. Eighty of the remaining variables received greater than $66.6 \%$ and less than $100 \%$ consensus, six were undecided (50-66.6\%) and one variable did not achieve consensus $(<50 \%)$ (Supplementary Table 2). A total of 86 potential core variables (less than complete consensus (80) and undecided (6) variables)) were fed into the second round of the Delphi process.

Additionally, 54 suggest variables had attained at least two or more votes by the Delphi panel and moved on to the second round of the Delphi process (R2) (Supplementary Table 2). The remaining 578 suggest variables were then appropriately reviewed and removed from the Delphi process.

Potential core variables with undecided consensus were: the GINA (Global Initiative for Asthma) asthma control questionnaire and patient status as a research subject. The asthma medication question regarding anti-leukotriene level received less than 50\% consensus and was removed from the ISAR potential core variable list and the Delphi review process after assessment by the Delphi neutral facilitator.

\section{Delphi R2}

Thirteen panel members participated in R2 (48\%). Eighty-six (less than complete consensus (80) and undecided (6) variables) potential core variables were considered in R2. Of them, 74 achieved consensus with more than $66.6 \%$ agreement for inclusion into the ISAR core variable list. Of the remaining variables, eight were undecided and four did not achieve consensus. In addition, nine of 54 variables in the suggest variable list attained more than $66.6 \%$ agreement for inclusion into the ISAR core variable list (Supplementary Table 3).

Of the eight undecided variables, comorbidities (Ischaemic Heart Disease and Heart Failure), asthma medication (Inhaled corticosteroid [ICS], Long-acting beta-agonist [LABA], long-acting muscarinic antagonist [LAMA]) and allergen testing details were included in Delphi R3. As suggested by Delphi 
exacerbation event?" was changed to a branch question versus a stand-alone question and added to the core variable list after a thorough review by the neutral facilitator.

Variables without consensus were: patient involvement in research trials, use of a nebuliser, SABA (short acting beta-agonists) and experience of adverse events. After further review by the Delphi neutral facilitator, these variables were removed from the core variable list.

Results from R2 were presented and discussed at the inaugural Steering Committee meeting in March 2017. The GINA Asthma Control questionnaire was chosen as the patient-reported measure of asthma control, and therefore included in the core variable list. Due to highly related variables, the nine newly suggest variables were consolidated into four variables after detailed discussion and review among the Delphi panel. Altogether, eight undecided potential core variables and the four consolidated suggest variables were included into R3 of the Delphi process.

\section{Delphi R3}

Fourteen Delphi members participated in R3 (51.9\%). Four of 12 R3 potential core variables achieved consensus with more than $66.6 \%$ agreement for inclusion into the ISAR core variable list (Supplementary Table 4). Of the remaining eight variables, five were undecided, and three did not achieve consensus. Upon review by the Delphi neutral facilitator, and a face-to-face discussion with the Steering Committee in May 2017, one undecided variable was included into the core variable list. All three non-consensus variables and remaining four undecided variables were removed from the core list. R3 resulted in five variables added to the core variable list. With all "potential core" variables achieving a status of consensus or non-consensus, the Delphi exercise ended at R3.

To further streamline the process, undecided variables and non-consensus variables such as asthma medication devices, prior clinical management plan, adverse events and comorbidities (Ischaemic Heart Disease and Heart Failure) were removed from the core variable list. Date of bone densitometry was added to the core list after ISC discussion, despite the undecided status.

372 During the conclusion of R3 at the second ISAR Steering Committee meeting in May 2017, a majority of the Delphi panel, all steering committee members (22 of 27) and the Delphi neutral facilitator agreed 
that ISAR should include two broad categories of patients similar to the European Respiratory Society

375 (ERS)/American Thoracic Society (ATS) Task Force's definition of Severe Asthma: patients receiving

376 GINA Step 5 treatment, and patients with uncontrolled asthma at some point while receiving GINA

377 Step 4 treatments (3). Patients were considered to have uncontrolled asthma were defined as those

378 having severe asthma symptoms, consisting of poor symptom control, airflow limitation, or serious

379 exacerbations as per the ERS/ATS guidelines, or suffering exacerbations requiring two or more courses

380 of oral corticosteroids.

381 The overall results from the Delphi process are summarised in Figure 2.

382 Final ISAR core variable list

383 The core variables that achieved consensus via the closely guided three rounds of Delphi were included

384 in the final core variable list (Table 3). The final ISAR core variable list consists of 95 variables, 83

385 variables that require data entry and 12 variables that do not require data entry (auto-populated). These

386 variables are classified into 13 variable categories.

387 The core variables were reported in a CRF, which allowed a probing mechanism to take place with a

388 branched questionnaire. A CRF was constructed to facilitate the process of data collection with 389 enhanced clarity. 


\section{Discussion}

392 The aim of this Delphi-based study was to reach consensus among specialists in the field of severe asthma on a core set of data fields to include in the International Severe Asthma Registry. Using the knowledge and experience of an international panel of severe asthma experts, workable criteria for registry purposes, a core set of variables and a potential method to unify data for severe asthma from across the globe were generated. Analyses of these registry data will facilitate insight into this heterogeneous disease on a global scale. All potential variables underwent a rigorous, stepwise consensus process to ensure the collection of the minimum required information to effectively study the development, therapeutics and management of patients with severe asthma.

Definitions, such as severe asthma, were based on expert opinion and precedence of use, because achieving consensus of what constituted severe asthma at an early stage in the process was important. The inclusion criteria, patients on GINA Step 5 therapy or uncontrolled on Step 4 therapy, were agreed upon by a majority of the panel to ensure the inclusion of severe asthma patients in a real-world setting. These criteria served the primary purpose of the registry to prospectively survey severe asthma patients. In addition, the inclusion criteria allowed the core data to be used for broader purposes (e.g. uncontrolled asthma etc.). The ISAR is not intended to assess the validity of real-life clinical practice, but merely to observe the evolving patterns of clinical care to ultimately evaluate its safety and/or effectiveness in order to improve the lives of patients. As such, no confirmation of asthma is required for enrolled subjects.

Of the initially circulated potential core and suggest variables, 95 variables achieved Delphi panel consensus. These variables represented 13 categories pertaining to the assessment and treatment of patients with severe asthma. Each category will serve to collect subsets of information essential for a more complete understanding of the disease. The successful limitation of core variables to less than 100 has resulted in an applicable CRF with a relatively small data entry burden for healthcare professionals who are participating in the registry. The specific domains that will enhance global registry recruitment and utility are discussed below. 
417 Patient details and medical history

418 Patient demographic and medical history data fields will allow patients to be categorised (16). The 419 panel-approved variables were chosen to ensure a comprehensive set of patient characteristics are 420 collected for patient aggregation. Previous studies have shown that many patients overestimate their

421 level of asthma control and underestimate the severity of their condition, indicating that they tolerate 422 symptoms and lifestyle limitations (17-19). The GINA questionnaire was the preferred tool for this 423 assessment, because previous studies have shown that it does not overestimate the proportion of patients 424 with controlled asthma and is therefore more likely to give a less exaggerated score compared to other available questionnaires (20).

\section{Diagnostics}

427 The expert panel agreed to collect screening and diagnostic results to help identify the care requirements of individual patients. Biomarkers such as peripheral blood and sputum eosinophils, and fractional exhaled nitric oxide (FENO) have been shown to be useful for the management of asthma $(21,22)$, and may help identify specific subtypes of severe asthma likely to benefit from treatment with novel biological agents.

\section{Adherence and comorbidities}

433 Non-adherence to therapy is approximately 50\% in adults with severe asthma (23-25). Physicians need 434 to ensure that patients are satisfied with their medication to increase adherence and optimise disease control (26). The potential for ISAR to investigate non-adherence across different geographical regions, with likely different healthcare systems, availability of medications and access to specialists and asthma education, was noted.

438 A real-life study on asthma control reported that physicians believed that the main reasons for lack of 439 asthma control included comorbidities, as seen in $36.2 \%$ of patients, continued exposure to 440 irritants/triggers in $34.0 \%$ of patients, and inadequate adherence to treatment in $27.0 \%$ of patients (27).

\section{Treatment management plan}

442 Asthma patient management practices among adults have been found to be inadequate in many practices 443 in Europe (28). Along with the information that ISAR will collect on clinical outcomes and 
demographic characteristics, the best treatment management plan by patient group will be assessed. Moreover, the panel agreed to collect broad treatment options to ensure that all participating countries will be able to contribute without subjection to individual country specifications.

\section{$447 \quad$ Strengths and weaknesses}

448 The Delphi panel was composed of international severe asthma professionals to ensure that recommendations recognised and reflected all social nuances specific to the participating countries while maintaining applicability in more than one healthcare setting and location. Eighteen unique Delphi panel members from 16 different countries participated in one or more Delphi rounds. This allowed broad consensus to be obtained. Using a group approach ensured that more comprehensive expertise was extrapolated than from any individual member alone. The selected panel of experts were chosen not only for their expertise in the research field, but also for their relevant medical practice and experience with developing and/or managing databases or regional/national severe asthma registries. The Delphi method ensured versatility of application and enhanced the sustainability of ISAR in the field due to panel members' involvement and cooperation in the generation of the registry data specification.

The anonymity of the survey helped to reduce the influence of dominant individuals which may become apparent during face-to-face meetings. However, the anonymity may also have reduced the positive effects of interaction during face-to-face meetings, depriving experts of important exchanges of information which would help to identify and discuss reasons for disagreement (29). The modified Delphi process maximised the benefits of both consensus methods through the initial collection of information via questionnaires followed by structured in-person meetings. ISAR meetings were organised to allow panel and/or steering committee members to discuss variables and selection criteria and resolve remaining disagreements face to face.

The Delphi process was predominantly carried out online and was therefore efficient and economically viable in terms of investigator time and funding. Furthermore, it facilitated rapid communication between a global panel of experts. However, the response rate was not $100 \%$, with a total of 18 out of 27 experts $(62 \%)$ responding to the three Delphi rounds. Although early experiments using Delphi 
suggested that group error was reduced with increased group size (30), more recent studies have found

472 that reliable outcomes can be obtained with a relatively small number of Delphi experts (31). The

473 number of specialised experts in a specific field may be limited. The consistency of expert training may

474 allow small numbers of experts to reliably participate in the generation of valid stable responses. The

475 selection of the panel is therefore extremely important. However, due to the consistency in the number

476 of experts who participated in each round $(\mathrm{R} 1=15, \mathrm{R} 2=13, \mathrm{R} 3=14)$, the possibility of reaching a

477 consensus was conserved.

478 The Delphi panel was not fully representative of the diversity amongst stakeholders of respiratory

479 health, such as healthcare payers or patients. The wide range of opinions gathered could be bolstered with an increase in the variety of stakeholders.

The design of the Delphi process, which involved the gathering of opinions from a group of experts, dilutes the opinion of a single expert. Thus, bias is decreased and diversity within the expert panel is maximised, which in turn decreases the possibility of overlooking the obvious facets of the questions. Despite the incomplete response rate and possible changes in experts participating in each round, the final results covered a wide range of areas where consensus was achieved. It is important to remember that the Delphi method is a tool to be used in conjunction with other processes which can be used to answer a wide range of research questions.

It is beyond the scope of this study to investigate the reasons behind the convergent or divergent views of the panel. However, these reasons should be explored next to further validate the methodology of a Delphi exercise.

\section{Conclusion}

Using the Delphi process to gain an international consensus among severe asthma experts across sixteen countries, a standardised framework was developed to describe patients with severe asthma, which may help to define a link between best practices and improved outcomes. These questions cover a comprehensive range of variables from patient demographics, diagnostics, patient- or physicianreported outcomes and treatment management plans. Collecting a minimum necessary amount of real- 
497 life data on a severe asthma patient will not only enhance the quality of patient care, but also ensure the 498 sustainability of ISAR as an international registry given that there are often limited resources available 499 for data collection. This is the first attempt to develop such a registry on a global scale within the setting 500 of severe asthma. The main goal of this effort is to standardise data collection to enable pooling of 501 multiple data sources and assist in clinical decision-making for healthcare professionals around the 502 world. The next step is to enrol patients and collect data that will allow gaps in diagnosis and treatment 503 to be identified, and solutions to be found, which will help bridge these gaps and thus bring us one step 504 closer to controlling severe asthma.

\section{Acknowledgements}

506 The International Severe Asthma Registry is conducted by Optimum Patient Care Global Limited, and 507 co-funded by Optimum Patient Care Global and AstraZeneca. 
$510 \quad$ 1. Martinez FD, Vercelli D. Asthma. Lancet. 2013;382(9901):1360-72.

5112 2. (GINA) GIoA. Global strategy for asthma management and prevention 2017 [cited 201721

512 June]. Available from: http://ginasthma.org/2017-gina-report-global-strategy-for-asthma-

513 management-and-prevention/.

514 3. Chung KF, Wenzel SE, Brozek JL, Bush A, Castro M, Sterk PJ, et al. International ERS/ATS guidelines on definition, evaluation and treatment of severe asthma. Eur Respir J. 2014;43(2):343-73. 4. Wenzel S. Severe asthma in adults. Am J Respir Crit Care Med. 2005;172(2):149-60. 5. von Bulow A, Kriegbaum M, Backer V, Porsbjerg C. The prevalence of severe asthma and low asthma control among Danish adults. J Allergy Clin Immunol Pract. 2014;2(6):759-67.

6. Bel EH, Sousa A, Fleming L, Bush A, Chung KF, Versnel J, et al. Diagnosis and definition of severe refractory asthma: an international consensus statement from the Innovative Medicine Initiative (IMI). Thorax. 2011;66(10):910-7.

7. Gliklich RE DN, Leavy MB. In: (US) AfHRaQ, editor. Registries for Evaluating Patient Outcomes: A User's Guide. 3rd ed. Rockville (MD)2014.

8. Maio S, Baldacci S, Bresciani M, Simoni M, Latorre M, Murgia N, et al. RItA: The Italian severe/uncontrolled asthma registry. Allergy. 2017.

9. Heaney LG, Brightling CE, Menzies-Gow A, Stevenson M, Niven RM, British Thoracic Society Difficult Asthma N. Refractory asthma in the UK: cross-sectional findings from a UK multicentre registry. Thorax. 2010;65(9):787-94.

10. Maio S, Baldacci S, Cerrai S, Sarno G, Bresciani M, Latorre M, et al. The Italian registry for severe/uncontrolled asthma. European Respiratory Journal. 2016;48(suppl 60).

11. PROTOCOL - SAWD \& Research Register Version 4.0. 2015. [cited 201809 April]. Available from: http://www.severeasthma.org.au/wp-content/uploads/2017/09/PROTOCOL-SAWDResearch-Register-Version-4.0-1st-December-2015.pdf.

12. Senna G, Guerriero M, Paggiaro PL, Blasi F, Caminati M, Heffler E, et al. SANI-Severe Asthma Network in Italy: a way forward to monitor severe asthma. Clin Mol Allergy. 2017;15:9. 13. Harvey E, Gibson P, Bardin P, Peters M, Reynolds P, Upham J, Reddel H, Kritikos V, Katelaris C, Cochrane B, Thien F, Azad A, Hew M, Yang I, Brockway B, Garrett J, Yap E, Jones S, Southcott A, Jayaram L, E.g. Gillman A, Uddin N, Rimmer J, Katsoulotos G, Smith V, Jenkins C, Wark P, McDonald V. Asthma and Allergy SIG 2 Poster Presentations; Characterisation of severe asthma phenotypes via a severe asthma registry: The severe asthma Web-based database. Respirology. 2016;21(Issue S2):108-15.

14. Pill J. The Delphi method: Substance, context, a critique and an annotated bibilography. Socio-Economic Planning Science. 1971;5:55-71.

15. Eubank BH, Mohtadi NG, Lafave MR, Wiley JP, Bois AJ, Boorman RS, et al. Using the modified Delphi method to establish clinical consensus for the diagnosis and treatment of patients with rotator cuff pathology. BMC Med Res Methodol. 2016;16:56.

16. Thomson NC, Chaudhuri R, Livingston E. Asthma and cigarette smoking. Eur Respir J. 2004;24(5):822-33.

17. Partridge MR, van der Molen T, Myrseth SE, Busse WW. Attitudes and actions of asthma patients on regular maintenance therapy: the INSPIRE study. BMC Pulm Med. 2006;6:13.

18. Price D, Fletcher M, van der Molen T. Asthma control and management in 8,000 European patients: the REcognise Asthma and LInk to Symptoms and Experience (REALISE) survey. NPJ Prim Care Respir Med. 2014;24:14009.

19. Rabe KF, Adachi M, Lai CK, Soriano JB, Vermeire PA, Weiss KB, et al. Worldwide severity and control of asthma in children and adults: the global asthma insights and reality surveys. J Allergy Clin Immunol. 2004;114(1):40-7.

20. Vermeulen F, de Meulder I, Paesmans M, Muylle I, Bruyneel M, Ninane V. Asthma control measurement using five different questionnaires: a prospective study. Respir Med. 2013;107(9):131421.

21. Smith AD, Cowan JO, Brassett KP, Filsell S, McLachlan C, Monti-Sheehan G, et al. Exhaled nitric oxide: a predictor of steroid response. Am J Respir Crit Care Med. 2005;172(4):453-9. 
22. Pavord ID, Korn S, Howarth P, Bleecker ER, Buhl R, Keene ON, et al. Mepolizumab for severe eosinophilic asthma (DREAM): a multicentre, double-blind, placebo-controlled trial. Lancet. 2012;380(9842):651-9.

23. Boulet LP, Vervloet D, Magar Y, Foster JM. Adherence: the goal to control asthma. Clin Chest Med. 2012;33(3):405-17.

24. De Smet BD, Erickson SR, Kirking DM. Self-reported adherence in patients with asthma. Ann Pharmacother. 2006;40(3):414-20.

25. Gamble J, Stevenson M, McClean E, Heaney LG. The prevalence of nonadherence in difficult asthma. Am J Respir Crit Care Med. 2009;180(9):817-22.

26. van Boven JF, Ryan D, Eakin MN, Canonica GW, Barot A, Foster JM, et al. Enhancing Respiratory Medication Adherence: The Role of Health Care Professionals and Cost-Effectiveness Considerations. J Allergy Clin Immunol Pract. 2016;4(5):835-46.

27. Allegra L, Cremonesi G, Girbino G, Ingrassia E, Marsico S, Nicolini G, et al. Real-life prospective study on asthma control in Italy: cross-sectional phase results. Respir Med. 2012;106(2):205-14.

28. Vermeire PA, Rabe KF, Soriano JB, Maier WC. Asthma control and differences in management practices across seven European countries. Respir Med. 2002;96(3):142-9.

29. Keeney S, Hasson F, McKenna HP. A critical review of the Delphi technique as a research methodology for nursing. Int J Nurs Stud. 2001;38(2):195-200.

30. Adler M, Ziglio E. Gazing into the oracle: The Delphi method and its application to social policy and public health: Jessica Kingsley Publishers; 1996.

31. Akins RB, Tolson H, Cole BR. Stability of response characteristics of a Delphi panel: application of bootstrap data expansion. BMC Med Res Methodol. 2005;5:37.

32. Vrijens B, Dima AL, Van Ganse E, van Boven JF, Eakin MN, Foster JM, et al. What We Mean When We Talk About Adherence in Respiratory Medicine. The journal of allergy and clinical immunology In practice. 2016;4(5):802-12. 
Table 1: Sample of the "Potential Core" variable list from the International Severe Asthma Registry Delphi workbook Round 1

\begin{tabular}{|c|c|c|c|c|c|c|}
\hline Page & $\begin{array}{l}\text { Potential } \\
\text { Core } \\
\text { Variables }\end{array}$ & $\begin{array}{c}\text { Field } \\
\text { Format }\end{array}$ & $\begin{array}{l}\text { Response Option } \\
\text { (where applicable) }\end{array}$ & $\begin{array}{c}\text { Unit } \\
\text { (where } \\
\text { applicable) }\end{array}$ & $\begin{array}{l}\text { Place in } \\
\text { core } \\
\text { list? }\end{array}$ & $\begin{array}{l}\text { Reason } \\
\text { for } \\
\text { choice (if } \\
\text { "No") }\end{array}$ \\
\hline \multirow{7}{*}{ Patient details } & Date of visit & Date & & DDMMYY & & \\
\hline & Date of birth & Date & & DDMMYY & & \\
\hline & Gender & $\begin{array}{l}\text { Radio } \\
\text { button }\end{array}$ & Female/Male & & & \\
\hline & Ethnicity & $\begin{array}{l}\text { Drop- } \\
\text { down } \\
\text { menu }\end{array}$ & $\begin{array}{l}\text { Caucasian/ South- } \\
\text { East Asian/ North- } \\
\text { East Asian/ African/ } \\
\text { Mixed/ Other }\end{array}$ & & & \\
\hline & Height & Decimal & & $\mathrm{M}$ & & \\
\hline & Weight & Number & & $\mathrm{Kg}$ & & \\
\hline & $\begin{array}{l}\text { Bronchial } \\
\text { thermoplasty }\end{array}$ & $\begin{array}{l}\text { Radio } \\
\text { button }\end{array}$ & & & & \\
\hline
\end{tabular}


Table 2: Sample of the "Suggest" variable list from the International Severe Asthma Registry Delphi workbook Round 1

\begin{tabular}{|c|l|l|l|l|l|l|}
\hline \multirow{5}{*}{ Page } & \multicolumn{1}{|c|}{ Suggest Variables } & $\begin{array}{c}\text { Field } \\
\text { Format }\end{array}$ & $\begin{array}{c}\text { Response } \\
\text { Option } \\
\text { (where } \\
\text { applicable) }\end{array}$ & $\begin{array}{c}\text { Unit (where } \\
\text { applicable) }\end{array}$ & $\begin{array}{c}\text { Propose } \\
\text { for core } \\
\text { list? }\end{array}$ & $\begin{array}{c}\text { Reason } \\
\text { for } \\
\text { choice (if } \\
\text { "Yes") }\end{array}$ \\
\hline \multirow{5}{*}{ Sputum } & Neutrophils & Decimal & & $\%$ & & \\
\cline { 2 - 7 } & Eosinophils & Decimal & & $\%$ & & \\
\cline { 2 - 7 } & Date of sputum & Date & & DDMMYY & & \\
\cline { 2 - 7 } & $\begin{array}{l}\text { Sputum processing } \\
\text { protocol }\end{array}$ & Text & & & & \\
\cline { 2 - 7 } & Bronchial epithelial cells & Decimal & & $\%$ & & \\
\cline { 2 - 7 } & Bronchial epithelial cells & Decimal & & $10 \% / L$ & & \\
\cline { 2 - 7 } & Macrophages & Decimal & & $\%$ & & \\
\cline { 2 - 7 } & Lymphocytes & Decimal & & $\%$ & & \\
\cline { 2 - 7 } & $\begin{array}{l}\text { Samples stored locally for } \\
\text { biobanking }\end{array}$ & $\begin{array}{l}\text { Radio } \\
\text { button }\end{array}$ & No/Yes & & & \\
\hline
\end{tabular}




\begin{tabular}{|c|c|}
\hline Category & Variable Field Name \\
\hline Inclusion Criteria & $\begin{array}{l}\text { 1) Receiving GINA Step } 5 \text { therapy } \\
\text { 2) Uncontrolled receiving GINA Step } 4 \text { (ERS/ATS Guidelines) therapy: } \\
\text { a. Having severe asthma symptoms including poor symptom control, airflow } \\
\text { limitation, and serious exacerbations } \\
\text { b. Frequent severe asthma exacerbations requiring systemic corticosteroids. } \\
\text { Patient fulfils the inclusion criteria for ISAR }\end{array}$ \\
\hline Patient Details & $\begin{array}{l}\text { Date of visit } \\
\text { Date of birth } \\
\text { Age at assessment } \\
\text { Gender } \\
\text { Ethnicity } \\
\text { Body Surface Area } \\
\text { Body Mass Index } \\
\text { Height } \\
\text { Weight } \\
\text { Bronchial Thermoplasty }\end{array}$ \\
\hline Occupation & Current occupation of the patient \\
\hline Medical History & $\begin{array}{l}\text { Current smoking status of patient } \\
\text { Pack years } \\
\text { - Number of cigarettes smoked per day } \\
\text { Years since smoked } \\
\text { Age at which asthma symptom began } \\
\text { Number of exacerbations requiring rescue steroids in the past } 12 \text { months } \\
\text { Number of episodes of invasive ventilation ever } \\
\text { Number of A\&E attendances for asthma in the past } 12 \text { months } \\
\text { Number of hospital admissions for asthma in the past } 12 \text { months }\end{array}$ \\
\hline Comorbidity & $\begin{array}{l}\text { Eczema } \\
\text { Allergic Rhinitis } \\
\text { Chronic Rhinosinusitis } \\
\text { Nasal Polyps } \\
\text { Atopic Disease (Atopic Dermatitis and allergic rhinitis). }\end{array}$ \\
\hline
\end{tabular}


Table 3: Cont.

\begin{tabular}{|c|c|}
\hline Category & Variable Field Name \\
\hline Blood/Sputum & $\begin{array}{l}\text { Highest blood eosinophil count within the past year } \\
\text { Date of highest blood eosinophil count within the past year } \\
\text { Was this highest blood eosinophil count during an exacerbation event } \\
\text { Highest blood eosinophil count within the past year and not during exacerbation } \\
\text { Date of highest blood eosinophil count within the past year and not during exacerbation } \\
\text { Current blood eosinophil count } \\
\text { Date of current blood eosinophil count } \\
\text { Highest sputum eosinophil count within the past year } \\
\text { Date of highest sputum eosinophil count within the past year } \\
\text { IgE count } \\
\text { Date of IgE count }\end{array}$ \\
\hline Diagnostics & $\begin{array}{l}\text { Chest CT scan } \\
\text { Date of chest CT scan } \\
\text { Bone densitometry (DEXA) } \\
\text { Date of bone densitometry (DEXA) }\end{array}$ \\
\hline Lung Function & $\begin{array}{l}\text { Pre-bronchodilator FEV1 } \\
\text { Post-bronchodilator FEV1 } \\
\text { Pre-bronchodilator FVC } \\
\text { Post-bronchodilator FVC } \\
\text { Predicted FEV1 } \\
\text { Pre-bronchodilator FEV1 (\% predicted) } \\
\text { Post-bronchodilator FEV1 (\% predicted) } \\
\text { Predicted FVC } \\
\text { Pre-bronchodilator FVC (\% predicted) } \\
\text { Post-bronchodilator FVC (\% predicted) } \\
\text { FEV1/FVC ratio pre-bronchodilator (\%) } \\
\text { FEV1/FVC ratio post-bronchodilator (\%) } \\
\text { PC20 methacholine/histamine test } \\
\text { Date of PC20 test } \\
\text { PC20 test result } \\
\text { Fractional Exhaled Nitric Oxide (FENO) test } \\
\text { Date of FENO test } \\
\text { FENO test result }\end{array}$ \\
\hline
\end{tabular}


Table 3: Cont.

\begin{tabular}{|c|c|}
\hline Category & Variable Field Name \\
\hline Allergen Testing & $\begin{array}{l}\text { Environmental Allergen Test } \\
\text { Serum allergy test: Positive to allergen } \\
\text { Serum allergy test: Specify positive allergen and result } \\
\text { Serum allergy test: Date } \\
\text { Skin prick test: Positive to allergen } \\
\text { Skin prick test: Specify positive allergen and result } \\
\text { Skin prick test: Date }\end{array}$ \\
\hline Asthma Control & $\begin{array}{l}\text { GINA Asthma Control Questionnaire } \\
\text { In the past } 4 \text { weeks, did the patient have: } \\
\text { Daytime symptoms more than twice per week } \\
\text { Any activity limitation } \\
\text { Any nocturnal symptoms/awakening } \\
\text { Reliever medication use more than twice per week } \\
\text { Lung function (PEF or FEV1) }<80 \% \text { of predicted or personal best }\end{array}$ \\
\hline $\begin{array}{c}\text { Asthma } \\
\text { Medication }\end{array}$ & $\begin{array}{l}\text { Maintenance Oral Corticosteroids } \\
\text { Start Date of Oral Corticosteroids } \\
\text { ICS+LABA combination therapy } \\
\text { Start Date of ICS+LABA combination therapy } \\
\text { ICS (only) } \\
\text { Start Date of ICS (only) therapy } \\
\text { LABA (only) } \\
\text { Start Date of LABA (only) therapy } \\
\text { LAMA } \\
\text { Start Date of LAMA therapy } \\
\text { Theophyllines } \\
\text { Start Date of Theophyllines therapy } \\
\text { Leukotriene Receptor Antagonist (LTRA) } \\
\text { Start Date of LTRA therapy } \\
\text { Anti-IgE Treatment } \\
\text { Start Date of Anti-IgE therapy } \\
\text { Anti-IL-5 Treatment } \\
\text { Start Date of Anti-IL5 therapy } \\
\text { Macrolide Antibiotic Treatment } \\
\text { Start Date of Macrolide Antibiotic therapy } \\
\text { Other steroid sparing agents }\end{array}$ \\
\hline
\end{tabular}


Table 3: Cont.

\begin{tabular}{|c|l|}
\hline Category & \multicolumn{1}{|c|}{ Variable Field Name } \\
\hline Adherence & Evidence of poor adherence $^{1}$ \\
\hline $\begin{array}{c}\text { Management } \\
\text { Plan }\end{array}$ & $\begin{array}{l}\text { Other factors contributing to severe asthma symptoms } \\
\text { Current Clinical Management } \text { Plan }^{3}\end{array}$ \\
\hline
\end{tabular}

1 "Evidence of poor adherence":

This variable has the response options: "No", "Yes: Subjective measure" and "Yes: Objective measure" Poor Adherence to Treatment can be indicated by selecting either (a) or (b):

(a) Subjective measure (e.g. Clinical Impression, self-ending): Opinion of a medical personnel for poor adherence to asthma medication therapy or patient self-report

- $\quad$ For example ${ }^{32}$.

i. Impression of "Non-persistence": Patient stops taking medication.

ii. Impression of "Non-implementation": Patient does not take medication as prescribed.

(b) Objective measure (e.g. Prescription Records, electronic monitoring): Evidenced by medical records detailing asthma medication prescriptions being issued and inadequately filled or electronic monitoring obtained by smart inhalers patterns.

- For example:

i. Medication Possession Ratio (MPR)= (Sum of days' supply for all fills/Number of days) $X 100 \%<80 \%$ threshold

2 "Other factors contributing to severe asthma symptoms":

This variable calls for a trained clinician's perception or opinion on any other external factors (if any) that could contribute to the severe asthma symptoms of the patient.

- For example:

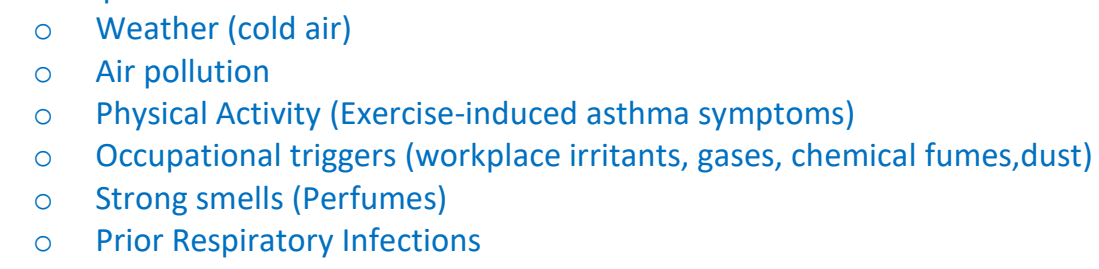

3 "Current Clinical Management Plan":

This variable aims to record the asthma action plan for a patient to review efficacy over time.

- For example:

- Entry into Clinical Trial

- If the patient is deemed suitable to benefit from a clinical trial drug

- Discharge to local asthma service

- If the patient has shown alleviated asthma symptoms

- Optimisation of current asthma therapy

- If the patient's current asthma therapy is titrated for better asthma management

- Bronchial Thermoplasty

- If the patient is eligible to have a bronchial thermoplasty surgery to manage their asthma

○ Biologic Therapy

- If the patient is prescribed biologic therapy

○ Others:

- Asthma education

- Inhaler use education 
Figure Legend

607

Figure 1: General flow of the International Severe Asthma Registry (ISAR) Delphi process showing topics discussed in each round

609

Figure 2: Summary of Delphi results for the International Severe Asthma Registry (ISAR)

610

611 


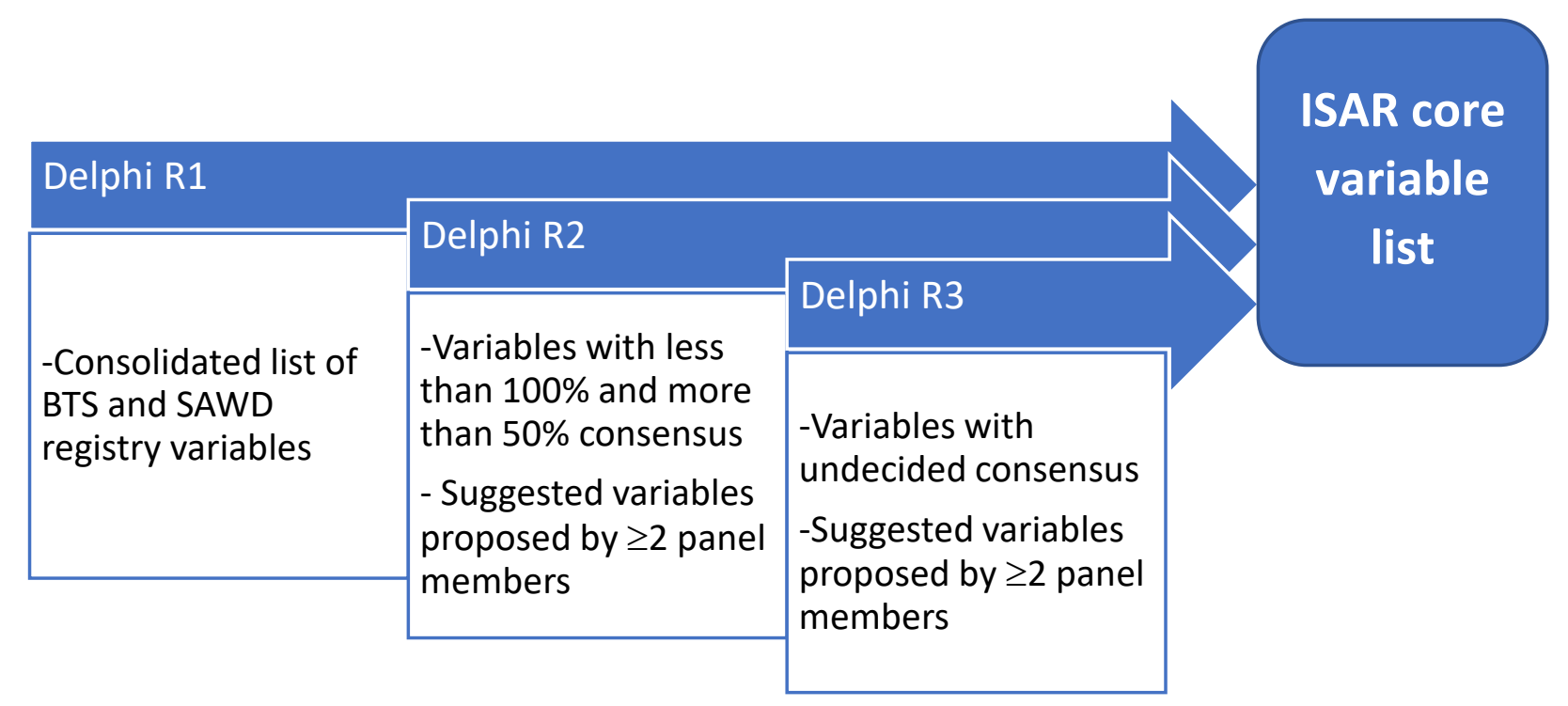

BTS, British Thoracic Society; SAWD, Severe Asthma Web-based Database 


\section{Potential core variable list: 115}

Combined BTS and SAWD registry

Delphi R1: 115 potential core variables

$100 \%$ complete consensus: 28

Less than complete consensus: 80

Undecided: 6

Without consensus: 1

Added to core: 28 variables

Delphi R2: 86 potential core variables

Consensus: 74

Undecided: 8

Without consensus: 4

Added to core: 74 variables

Delphi R3: 8 potential core +4 suggested variables

Consensus: 4

Undecided: 5

Without consensus: 3

Added to core: 4 variables
Suggested variable

list: 632
Delphi R1: 632 suggested variables

Selected variables: 54
Delphi R2: 54 suggested variables

Selected variables: 9

9 selected variables

were consolidated

into 4 at the inaugural

ISC meeting

4

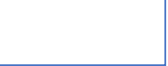

Delphi R3 results discussed and presented at the second ISC meeting

- Undecided variables added to core: 1

- Inapplicable variables removed from potential core (106) variables: 12

\section{Total ISAR core variables: 95}

BTS, British Thoracic Society; ISC, ISAR Steering Committee; SAWD, Severe Asthma Web-based Database 


\section{Supplementary Material}

Supplementary Table 1: International Severe Asthma Registry Delphi panel members

\begin{tabular}{|l|l|}
\hline Delphi Panel Member & Country \\
\hline David Price (independent facilitator) & Singapore \\
\hline Liam Heaney & United Kingdom \\
\hline Andrew Menzies-Gow & United Kingdom \\
\hline Giorgio Walter Canonica & Italy \\
\hline Eric Van Ganse & France \\
\hline Manon Belhassen & France \\
\hline Roland Buhl & Germany \\
\hline Anke-Hilse Maitland- van der Zee & The Netherlands \\
\hline Leif Bjermer & Sweden \\
\hline Peter Gibson & Australia \\
\hline Vibeke Backer & Denmark \\
\hline Chin Kook Rhee & South Korea \\
\hline Nikos Papadopoulos & Greece \\
\hline Rohit Katial & USA \\
\hline Lauri Lehtimäki & Finland \\
\hline J.Mark FitzGerald & Canada \\
\hline Guy Brusselle & Belgium \\
\hline Luis Perez de Llano & Spain \\
\hline Francisco de Borja Garcia-Cosio Piqueras & Spain \\
\hline Loo Chian Min & Singapore \\
\hline Sven Erik Dahlen & Sweden \\
\hline Mark Hew & Australia \\
\hline Matthew Peters & Australia \\
\hline Erin Harvey & Australia \\
\hline Katia M C Verhamme & The Netherlands \\
\hline Job FM van Boven & The Netherlands \\
\hline Mohsen Sadatsafavi & Canada \\
\hline & \\
\hline
\end{tabular}


Supplementary Table 2: Delphi R1 results summary

\begin{tabular}{|c|c|c|c|}
\hline R1 variable summary & Number & Criteria & Remarks \\
\hline \multicolumn{4}{|c|}{ Potential Core Variables } \\
\hline Total number of variables & 115 & & \\
\hline Undecided & 6 & 50 to $66.6 \%$ & Entered in R2 \\
\hline Without consensus & 1 & $<50 \%$ & Removed from core \\
\hline $\begin{array}{l}\text { Less than complete } \\
\text { consensus }\end{array}$ & 80 & $>66.6 \%$ and $<100 \%$ & Entered in R2 \\
\hline Complete consensus & 28 & $100 \%$ & Included in core \\
\hline \multicolumn{4}{|c|}{ Suggested Variables } \\
\hline Total number of variables & 632 & & \\
\hline Highly suggested & 54 & $\geq 2$ suggestions & Entered in R2 \\
\hline
\end{tabular}


Supplementary Table 3: Delphi R2 results summary

\begin{tabular}{|l|l|l|l|}
\hline \multicolumn{1}{|c|}{ R2 variable summary } & \multicolumn{1}{|c|}{ Number } & \multicolumn{1}{c|}{ Criteria } & Remarks \\
\hline \multicolumn{3}{|c|}{ Potential Core Variables } \\
\hline Total number of variables & 86 & & Entered in R3 \\
\hline Undecided & 8 & 50 to $66.6 \%$ & Removed from core \\
\hline Without consensus & 4 & $<50 \%$ & Included in core \\
\hline Consensus & 74 & $>66.6 \%$ & Suggested Variables \\
\hline \multicolumn{4}{|c|}{} \\
\hline Total number of variables & 54 & $\geq 2$ suggestions & $\begin{array}{l}\text { Consolidated to 4 at the inaugural } \\
\text { SC meeting and entered in R3 }\end{array}$ \\
\hline Highly suggested & 9 &
\end{tabular}


Supplementary Table 4: Delphi R3 results summary

\begin{tabular}{|l|l|l|l|}
\hline \multicolumn{1}{|c|}{ R3 variable summary } & \multicolumn{1}{c|}{ Number } & \multicolumn{1}{c|}{ Criteria } & \multicolumn{1}{c|}{ Remarks } \\
\hline Total number of variables & 12 & & \\
\hline Consensus & 4 & $>66.6 \%$ & Included in core \\
\hline Undecided & 5 & 50 to $66.6 \%$ & $\begin{array}{l}\text { 1 included in core } \\
\text { 4 removed from core }\end{array}$ \\
\hline Without consensus & 3 & $<50 \%$ & Removed from core \\
\hline
\end{tabular}

